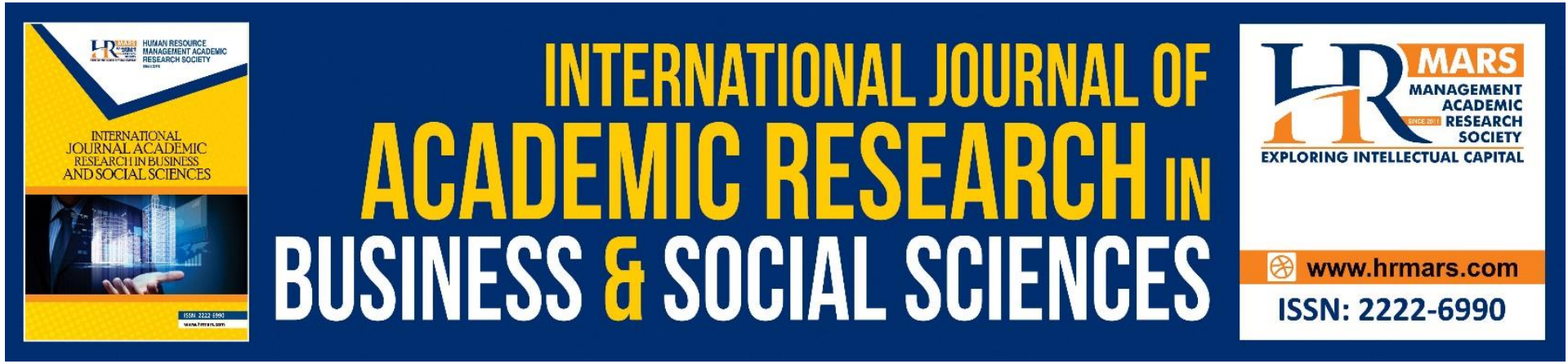

\title{
The Online Food Delivery Service and their Impact on Customer Satisfaction among University Students in Malaysia
}

Nazifa Insyirah binti Azman, Nurul Aqeelah binti Ahmad Mashuri, Syed Omar Al- Edruce bin Wan Ibrahim

To Link this Article: http://dx.doi.org/10.6007/IJARBSS/v11-i6/10014

DOI:10.6007/IJARBSS/v11-i6/10014

Received: 17 April 2021, Revised: 21 May 2021, Accepted: 30 May 2021

Published Online: 19 June 2021

In-Text Citation: (Azman et al., 2021)

To Cite this Article: Azman, N. I. binti, Mashuri, N. A. binti A., \& Ibrahim, S. O. A.-E. bin W. (2021). The Online Food Delivery Service and their Impact on Customer Satisfaction among University Students in Malaysia. International Journal of Academic Research in Business and Social Sciences, 11(6), 1665-1674.

Copyright: @ 2021 The Author(s)

Published by Human Resource Management Academic Research Society (www.hrmars.com) This article is published under the Creative Commons Attribution (CC BY 4.0) license. Anyone may reproduce, distribute, translate and create derivative works of this article (for both commercial and non-commercial purposes), subject to full attribution to the original publication and authors. The full terms of this license may be seen at: http://creativecommons.org/licences/by/4.0/legalcode

Vol. 11, No. 6, 2021, Pg. 1665 - 1674

Full Terms \& Conditions of access and use can be found at http://hrmars.com/index.php/pages/detail/publication-ethics 


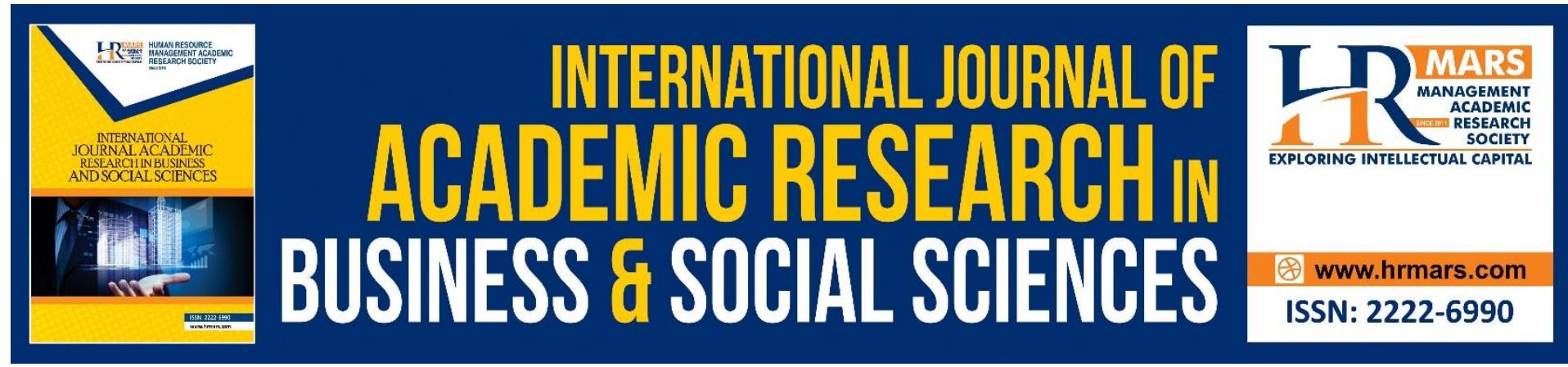

\title{
The Online Food Delivery Service and their Impact on Customer Satisfaction among University Students in Malaysia
}

\author{
Nazifa Insyirah binti Azman, Nurul Aqeelah binti Ahmad \\ Mashuri, Syed Omar Al- Edruce bin Wan Ibrahim \\ Faculty of Business Management and Professional Studies, Management and Science
}

University Malaysia

\begin{abstract}
Consumer satisfaction with the delivery of online food is an indicator of how a company's service is delivered to meet customer needs. One of the most notable measures of delivery quality, price, security/ privacy and time is customer satisfaction. Customer satisfaction is affected by multiple factors, such as time, climate, current situation and others. However, there are four considerations that should be taken into account, which are delivery service, time, security/privacy, and price as it will shape customer satisfaction among university students. The purpose of this research is to examine the effect of delivery service, time, security/privacy, and price on online food delivery services among university students. While the measurement of the variables was adopted from previous studies, data was collected from students in six universities in Malaysia which were selected conveniently. The obtained data was analysed using multiple regression. The results showed that all the independent variables which are delivery service, time, security/privacy, and price have significant relationship with satisfaction, with delivery service has the most significant relationship.

Keywords: Customer Satisfaction, Delivery Service, Time, Security/ Privacy and, Price, Food Delivery, Malaysia
\end{abstract}

\section{Introduction}

The online food distribution service has become a replacement platform for online ordering. The food delivery business has become very common, especially among young and busy people. It is therefore extremely crucial that online services recognize the nature and necessities, as because during this rising market, consumers need to have the relevant aspects of the total industry that are assumed as a control measures. Rapid development for online food placing orders in Malaysia have led to a growing demand among restaurant industry service providers. This study aims to identify the key factors that level customer satisfaction with their relevant service providers by answering the research question in the sense of Malaysia's online food business sector. Online Food Delivery (OFD) has become a trend in Malaysia. This new approach of ordering and receiving is expected to grow in popularity and can be tapped by businesses to reach bigger shares through collaborating with food delivery companies such as DahMakan, Other Kitchen, Cooked, and many more. It appears that the 
OFD service sector is virtually limitless, and the essence of this business is largely unknown (yeo, Goh \& Rezaei, 2017). However, to achieve a competitive edge, offering excellent service to improve customer satisfaction is essential in every service industry (Caro \& Garcia, 2007). Past researchers show that businesses with a strong competitive edge should first gain a positive reaction from consumers before improving productivity (Caro \& Garcia, 2007). This positive process is governed by a satisfied consumer with the expected performance after observing the quality of service. In addition, this attitude approach is vital for the organization to fully understand the quality of its service in mobile commerce (Jaz, AlSabah \& Sarfraz, 2018). So, in order to gain customer satisfaction, businesses need to have excellent services. This is because the quality of service has a good effect on customer satisfaction (Ozer, Argan \& Argan, 2013).

The demand for consumers to purchase food through online platforms in this new paradigm of a global pandemic has grown massively, particularly when consumers are compelled to stay at home. Research is yet to reach full understanding of how online food delivery can affect satisfaction among customers in the food sector and particularly among students. The current papers is fuelled by the apparent need for better understanding of the different phenomena that are directly or indirectly related to Malaysia students in Malaysia and elsewhere (Alharbi et al., 2018; Mosbah et al., 2018; Mosbah and Kalsom 2018a; Mosbah and Kalsom, 2018b; Aljubari et al., 2019; Mosbah et al., 2019a; Mosbah et al, 2019b). We must thoroughly understand the meaning of all and see if it will have a positive or negative effect before we analyse in detail the relation between customer satisfaction, delivery service, time, security/privacy, and price First and foremost, the customer satisfaction in researching online food delivery service has been identified as a benchmark. A study done by Cyr et al. (2008); Liu et al (2008); Shankar et al (2003) have identified that customer service and delivery services provide a major customer satisfaction relationship. The main question is how can customer satisfaction clear up the relationship between delivery service, time, price, and security/privacy? As for delivery service, according to Kimes (2011); Ng, Wong, \& Chong (2017); Yeo et al (2017), the provision of OFD service for the restaurant industry strengthens order accuracy, increases reliability, and strengthens customer satisfaction in the crowded market. This rise is a challenge and an advantage for restaurants because it creates a strong rivalry. Besides, time is, according to Settle and Alreck (1991), one of the most critical issues people typically struggle with is the perceived time constraint. Time demands indicate how much time is required in relation to everyday activities and commitments. To this, adds the factor price which has a positive impact towards each other (Jin et al., 2012; MartínConsuegra et al., 2007; Konuk, 2018). Moreover, on the authority of Fernandes and Calamote (2016), unfair costs have been shown to have an effect on customer satisfaction. Last but not least, security/privacy. Previous research has shown a possible correlation between the low level of trust formed on the internet in relation to consumer security/privacy issues. In addition, Harris Interactive (2002) indicates that three key figures are sources of suspicion, businesses may pass sensitive data, transfers may not be safe, and hackers may be able to steal their personal details to someone without prior permission. Several forms of studies have been carried out to study the factors influencing customer satisfaction in OFD service. Nevertheless, very few emphasised that online food delivery services amongst university students, the effect of customer satisfaction was analysed. Thus, we will focus on how customer satisfaction impacts university students on the purchases of online food delivery service. In the interval, the objective of this research is to investigate the effect of delivery 
service, time, security/privacy and price on customer satisfaction among university students in Malaysia.

\section{Theoretical Framework}

\section{Delivery Service and Customer Satisfaction}

The technology factor influences customer loyalty through distribution or supply networks (Rudansky-Kloppers, 2014; Jiradilok et al., 2014). Moreover, it is the growth in the satisfaction of their buying habits among online shoppers and internet users as stated by Karim (2013). Any delayed delivery will negatively impact customer satisfaction, which contributes to the appraisal and the influence of consumers (Coşar, Panyi, \& Varga, 2017). According to Lee and Joshi (2007), further stimulating factors are kit or parcels, security devices, and customer relationship management. The crucial challenge of maintaining high supply or the quality of delivery processes pleases customers can be pictured, provided that people can purchase products from areas as remote like China to Europe, and Japan to Brazil. Impacts on the consumer of services from online food delivery providers such as Zomato, Swiggy, and Foodpanda found that a delivery distinction between price, and quality are preferable by most of the consumers (Chandrasekhar et al., 2019). On the authority of Kamakura et al (2002); Sulin Ba \& Johansson (2008), the consumers shall be provided with the services of service administration. The model introduces a systematic framework to analyse how engagement in company processes contributes to the perception value of the customers. The different associations presented in the model were empirically checked and evidence was found for the beneficial impact of the expectations of the SDS on understanding of the delivery service and customer satisfaction behaviour's level. This can be concluded by following hypothesis that:

H1: There is a positive effect of delivery service on customer satisfaction.

\section{Time and Customer Satisfaction}

The definition of time can be seen at multiple stages as the interpretation and representation of a studied event differ with the selected time level. (Valsiner, 1998; 2006, Van Geert). Occurrence can be quantified over time or researched within a short period of time. Development is conceptualised at various stages of time. (Lemke, 2000; Van Geert, 2006; Van Geert \& Fischer, 2007). When using online FDI, clients have differing wants and needs. Several researchers have reported a strong correlation between attitude and behavioural intention to use online services in terms of technology adoption (Chang, Yan \& Tseng, 2015; Ingham, 2017). As far as efficient direction, when going to web based shopping, clients frequently hope to "purchase time" (Jensen, 2012; Alreck and Settle, 2002). In another study, Wu (2003) described that interchanging societal daily routine and lack of time cause problems for customers to enjoy buying in physical stores such as malls and fast food restaurants. Wu (2003) mentioned that as long as there is saving time in virtual ordering, people with buying power will persist to use the service. The following hypothesis may conclude this:

H2: There is a positive effect of time on customer satisfaction

\section{Security/Privacy and Customer Satisfaction}

Referring to Ranganathan and Ganapathy (2002); Kim et al. (2008); and Lian and Lin (2008); Yousafzai et al. (2003), usage of technologies for protecting consumers from theft, malware, and phishing that has beneficial impacts on their buying choices on the internet, such as encryption, digital signatures and certificates. Trust in the security sector was associated with 
negative internet attitudes. Faith in production had an impact on the purchasing decision, but consumers were particularly impacted by security or privacy when it comes to handling their private details (George, 2002; Flavia'n and Guinalı'u 2006). If security requirements are high and the trading partner is hgh, confidence for behavioral factors such as a key factor, einvestors or sellers tend to be less concerned with more and personal outcomes. Referring to Salam et al (2005); Castaneda et al (2007); Liu et al (2005), internet privacy questions are twodimensional. The first was the data collection method itself and the other was the bad utilisation of online traders or businesses of this expertise. Trust affects consumer perceptions of online firms. These findings raise concerns about the protection and potential use of information by the supplier. In consequence, on the author of Chellappa and Pavlou (2002), it helps customers to develop a trust, which in turn allows online purchases when protection or security and privacy policy are specifically identified. The following hypothesis will conclude by saying:

H3: There is a positive effect of security/privacy on customer satisfaction.

\section{Price and Customer Satisfaction}

According to previous research, purchasing agreement has made the price as a monetary value in the product and services' exchange (Nagle et al, 2010). In the marketplace, price plays their roles in all purchase situations as it is also considered as the amount that should be sacrificed by the consumers in the economic outlay. Referring to the marketing researchers, the relationship between consumers and the price offered has shown an inclination if the sellers concern on what consumers' need and want (Hermann et al, 2007; Kukar-Kinney, Xia \& Monroe, 2017; Martin-Consue gra, Molina, \& Esteban, 2007; Hanif, Hafeez, \& Riaz, 2010). Products or services that have been produced by sellers with a good quality and the price is affordable has tended consumers to have positive and good feelings towards sellers (Yieh et al, 2007). The consumers' acceptability on price could affect customer satisfaction in terms of product's quality with the price offered (Sheng et al., 2018; Kaura, Prasad, \& Sharma, 2016). Hence, this study can be concluded by the following hypothesis that:

H4: There is a positive effect of price on customer satisfaction 
Independent Variables

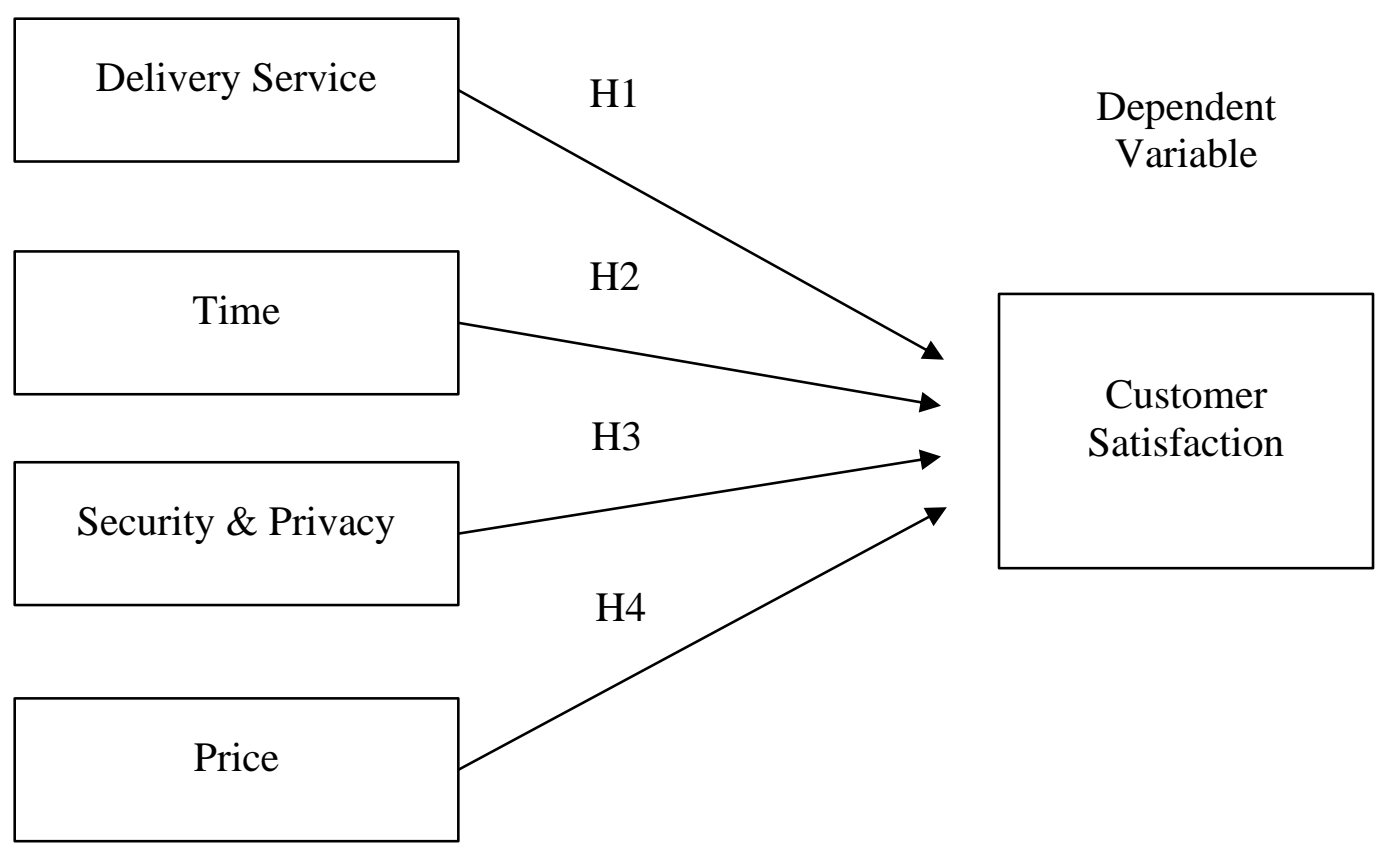

Figure 1: Research Framework

\section{Methodology}

This study is quantitative and aims to test a number of hypotheses that relates to effect on customer satisfaction in food delivery. The population of this study is undergraduate students from six universities in Malaysia who are taking different courses. The sample size for our research is 232 respondents and these sampled based on convenience sampling. As highlighted in table 1 , the measures used in this study were adopted from previous studies. 
Table 1: Measurement of variables

\begin{tabular}{|l|c|l|c|}
\hline \multicolumn{1}{|c|}{ Variables } & No of items & \multicolumn{1}{|c|}{ Sources } & Alpha \\
\hline $\begin{array}{l}\text { Customer } \\
\text { Satisfaction }\end{array}$ & 5 & Ding et al. (2011) & .917 \\
\hline Delivery Service & 7 & $\begin{array}{l}\text { Xia Liu, Mengqiao } \\
\text { He, Fang Gao \& } \\
\text { Peihong Xie (2008) }\end{array}$ & .895 \\
\hline Time & 4 & $\begin{array}{l}\text { Vincent Cheow Sern } \\
\text { Yen, See-Kwong Goh } \\
\text { \& Sajad Rezaei } \\
\text { (2016) }\end{array}$ & .804 \\
\hline Security/ Privacy & 4 & $\begin{array}{l}\text { Wolfinbargerhe \& } \\
\text { Gilly (2003) }\end{array}$ & \\
\hline Price & 5 & $\begin{array}{l}\text { Vincent Cheow Sern } \\
\text { Yen, See-Kwong Goh } \\
\text { \& Sajad Rezaei } \\
(2016)\end{array}$ \\
\hline
\end{tabular}

\section{Results and Discussion}

Table 2 below indicates the results of descriptive statistics, reliability and correlation in this study. Based on this table, the results for all variables are reliable in which the Cronbach alpha is ranged from .801 for the price to .873 for customer satisfaction. As for the mean scores, the students who answered our questionnaires showed positiveness because almost all variables were in a moderate to high range in a scale 3 to 4 . On the other hand, the correlation analysis among variables also shows moderate to high significant in which the highest correlation was between delivery service and customer satisfaction as it is recorded at $(r=$ .658 ) and the lowest correlation was between price and customer satisfaction as the results presented at $(r=.546)$. 
Table 2 Descriptive Statistics, Reliability and Correlation

\begin{tabular}{lcccccccc}
\hline Variables & Mean & SD & Alpha & $\begin{array}{c}\text { Customer } \\
\text { Satisfaction }\end{array}$ & $\begin{array}{c}\text { Delivery } \\
\text { Service }\end{array}$ & Time & $\begin{array}{c}\text { Security/ } \\
\text { Privacy }\end{array}$ & Price \\
\hline $\begin{array}{l}\text { Customer } \\
\text { Satisfaction } \\
(5)\end{array}$ & 4.0483 & .56912 & .873 & 1 & & & \\
& & & & & & & & \\
$\begin{array}{l}\text { Delivery } \\
\text { Service (7) }\end{array}$ & 4.1872 & .51804 & .829 & $.658^{* *}$ & 1 & & \\
$\begin{array}{l}\text { Time (4) } \\
\text { Security/ }\end{array}$ & 4.2134 & .57524 & .825 & $.637^{* *}$ & $.722^{* *}$ & 1 & & \\
$\begin{array}{l}\text { Privacy (4) } \\
\text { Price (5) }\end{array}$ & 3.7009 & .71240 & .850 & $.547^{* *}$ & $.425^{* *}$ & $.419^{* *}$ & 1 & \\
\hline
\end{tabular}

${ }^{* *} p<0.01$; number in brackets () are the number of measuring items

Table 3 indicates the multiple regression of this research in which it was measured to test the hypothesis. Based on this analysis, all the variables were predictors on customer satisfaction with varying degrees of strength. According to the table below, the highest predictor was delivery service $(\beta=0.357, p<0.001)$. The second stronger predictor was price as it is recorded at $(\beta=0.312, p<0.001)$. The third stronger predictor on customer satisfaction was time $(\beta=0.199, p<0.001)$ and the least predictor towards customer satisfaction was security/ privacy as the value recorded at $(\beta=0.180, p<0.001)$. According to Lee and Joshi (2007); Yieh et al. (2007), the above two values demonstrate significant effects on customer satisfaction on the purchase of food by way of online food delivery service. Referring to these findings, it is clear to say all the hypotheses were accepted and $63.1 \%$ explained the variance results of all variables as stated in the model (Adj. $\mathrm{R} 2=.631 ;(\mathrm{F}=96.844, p<.001)$.

Table 3 Multiple Regression predicting Customer Satisfaction

\begin{tabular}{|l|c|c|c|c|}
\hline \multicolumn{1}{|c|}{ Predictors } & Std. B & t-value & $p$ & $\begin{array}{c}\text { Hypothesis } \\
\text { status }\end{array}$ \\
\hline Delivery Service & .357 & 6.001 & .001 & Accepted \\
\hline Time & .199 & 3.303 & .001 & Accepted \\
\hline Security/ Privacy & .180 & 3.746 & .001 & Accepted \\
\hline Price & .312 & 6.880 & .001 & Accepted \\
\hline
\end{tabular}

Adj. $\mathrm{R} 2=.631 ;(\mathrm{F}=96.844, p<.001)$

\section{Conclusion and Contribution}

This study was primarily conducted to examine the effect of delivery services, time, security/privacy and price on food delivery satisfaction among students in Malaysia. The hypotheses built in this study were tested based on data collected from a sample of 
respondents. The results of this analysis indicate that the independent variables of delivery service, time, security/privacy, and price are related and linked to customer satisfaction which is the dependent variable. It is also obvious that customers will definitely not only inflict distress or discomfort, as they express their experience. They tell the distributor or retailer how to improve the efficiency of their items, services, and businesses. The customer service department or management should convey this challenge effectively. For the satisfaction of consumers, four variables; delivery service, time, security/privacy, and price influence the use of online food service by university students in Malaysia.

Based on the study done by Hanif, Hafeez, Riaz (2010); Lommeruda \& Sorgard (2003), consumers are not simply demanding and attentive to price equality, other factors such as brand loyalty and product coherence, have impaired their purchasing preference. According to Table 2 (descriptive statistics, reliability and correlation), it indicates that delivery service $(65.8 \%)$ has the highest impact on customer satisfaction. However, prices have the lowest effect of customer satisfaction, representing $54.6 \%$ out of $100 \%$. It can be concluded that the effect of price on online food delivery service is invaluable, but the main factor that is delivery service has the most influence towards the purchasing or ordering online food delivery service among university students in Malaysia.

As for practical contribution, it is related to the theoretical contributions in which the delivery service has the highest impact on customer satisfaction. Based on the table above, it is clear that there is an important value connecting delivery service and customer satisfaction. This practical contribution can be positing that most of the customer satisfaction has a positive effect on delivery service because it is convenient for them in terms of the ease, variety of choice and timesaving especially in this current situation that requires people to not to go out due to the COVID-19. This could help any businesses specifically food \& beverages (F\&B) restaurants to consider to use the online food delivery service as it is the major contributing customer using the delivery service.

\section{Limitations and Recommendations for Future Research}

The empirical findings revealed that there were two main limitations in this research study where the first one is regarding the number of populations. Due to COVID-19 that arose around the world including Malaysia, we found difficulties in approaching respondents physically due to the restriction that has been announced by the government to go out. The total number of respondents that we managed to collect only 232 students. Thus, we would like to recommend to the next researchers to expand the range of customers' population who are using this service. In this context, the number of populations can be increased since the researcher can approach not only students but workers, housewives or anyone as well. Besides,

Furtheremore, time constraints also one of our study's limitations as the time given to make a preparation of the questionnaire and finding respondents was only for two weeks. Since one of our independent variables which is the payment system was considered as weak, we have to redo our findings that are started from chapter 2 again. Thus, it has proven that we did not have enough time to complete our study. To get an efficient way to complete the thesis without wasting the time, we recommend to all the researchers to make further study regarding all variables that they want to choose before proceeding to the particular variables. Researchers may discuss with their supervisor whether the variables that they want to pick are strong enough to get the positive result in the hypothesis part. 


\section{References}

Saad, A. T. (2020), Factors Affecting Online Food Delivery Service in Bangladesh: An Empirical Study, British Food Journal 1(56), 1-16.

Alharbi, J., Almahdi, H., \& Mosbah, A. (2018). The impact of entrepreneurship education programs (EEPs) on the entrepreneurial attitudes among higher education students. International Journal of Management, Economics and Social Sciences, 7(3), 245-271.

Al-Jubari, I., Mosbah, A., \& Talib, Z. (2019). Do intrinsic and extrinsic Motivation Relate to Entrepreneurial Intention Differently? A Self-Determination Theory Perspective. Academy of Entrepreneurship Journal, 25, 1-14.

Dazmin, D., \& Ho, M. Y. (2019). The Relationship Between Consumers' Price-Saving Orientation and Time-Saving Orientation Towards Food Delivery Intermediaries (FDI) Services: An Exploratory Study. Global Scientific Journals, 7(2).

Florin L., I., \& Sergiu R. (n.d.). Theories of Consumers' Satisfaction and The Operationalization of the Expectation Disconfirmation Paradigm. "ACADEMICĂ BRÂNCUŞI" PUBLISHER, (2).

Juan, C. R., Juan, J. G., Juan, J. D. L. V. (2009). The importance of perceived trust, security and privacy in online trading systems, Information Management \& Computer Security, 17(2), 96-113.

Halaweh, M. (2018), Cash on Delivery (COD) as an Alternative Payment Method for ECommerce Transactions: Analysis and Implications, International Journal of Sociotechnology and Knowledge Development, 10(4), 1-4.

Mosbah, A., Ali, M. A., Aljubari, I. H., \& Sherief, S. R. (2018a). Migrants in the High-Tech and Engineering Sectors: An Emerging Research Area. In 2018 IEEE Conference on Systems, Process and Control (ICSPC) (pp. 234-237). IEEE.

Mosbah, A., Debili, R., \& Merazga, H. (2018b). First-generation immigrant entrepreneurship in Malaysia: What do we know so far?. Kasetsart Journal of Social Sciences, 39(2), 351357.

Mosbah, A., \& Wahab, K. A. (2018). Chinese family business in Malaysia: development, culture and the family business philosophy. International Journal of Academic Research in Business and Social Sciences, 8(5),1014-1021.

Mosbah, A., Abdul Hakim bin A. R., Al-Jubari, I. (2019a). Students and cultural issues in international contexts: The case of Malaysian international businesses students in UK and China. International Journal of Innovation, Creativity and Change, 5(2), 573-590.

Mosbah, A., Al-Jubari, I., \& Talib, Z. M. (2019b) Intention to Pursue Postgraduate Studies in Malaysian Universities, International Journal of Innovation, Creativity and Change, 5(2), 591-609

Varki, S., \& Colgate, M. (2001), The Role of Price Perceptions in an Integrated Model of Behavioral Intentions, Journal of Service Research, 3(2), 232-240.

Lau, T-C., \& Ng, D. (2019). Online Food Delivery Services: Making Food Delivery the New Normal. Journal of Marketing Advances and Practices, 1(1), 65-79.

Kedah, Z., Ismail, Y. A. K. M., Haque, A., \& Ahmed, S. (2015). Key Success Factors of Online Food Ordering Services: An Empirical Study. Malaysian Institute of Management, 50(2). 